\title{
Overall treatment outcome - analysis of long-term results of rectal cancer treatment on the basis of a new parameter
}

\author{
Michal Jankowski ${ }^{1,2}$, Dariusz Bała ${ }^{1,2}$, Manuela Las-Jankowska ${ }^{1,3}$, Wojciech Maria Wysocki ${ }^{4,5,6}$, \\ Tomasz Nowikiewicz ${ }^{1,7}$, Wojciech Zegarski ${ }^{1,2}$
}

\author{
${ }^{1}$ Chair of Surgical Oncology, Ludwik Rydygier Collegium Medicum in Bydgoszcz, \\ Nicolaus Copernicus University in Torun, Poland \\ 2Department of Surgical Oncology, Oncology Center - Prof. Franciszek Lukaszczyk \\ Memorial Hospital, Bydgoszcz, Poland \\ ${ }^{3}$ Department of Clinical Oncology, Oncology Center - Prof. Franciszek Lukaszczyk \\ Memorial Hospital, Bydgoszcz, Poland \\ ${ }^{4}$ Department of General, Oncological and Vascular Surgery, $5^{\text {th }}$ Military Clinical Hospital, \\ Krakow, Poland \\ ${ }^{5}$ Chair of Surgery, Faculty of Medicine and Health Sciences, Andrzej Frycz Modrzewski \\ Krakow University, Krakow, Poland \\ ${ }^{6}$ National Institute of Oncology, Maria Skłodowska-Curie Memorial, Scientific Editorial \\ Office, Krakow, Poland \\ ${ }^{7}$ Department of Breast Cancer and Reconstruction Surgery, Oncology Center - \\ Prof. Franciszek Lukaszczyk Memorial Hospital, Bydgoszcz, Poland
}

Submitted: 26 May 2017

Accepted: 12 November 2017

Arch Med Sci 2020; 16 (4): 825-833

DOI: https://doi.org/10.5114/aoms.2020.94330

Copyright (c) 2020 Termedia \& Banach

\section{Abstract}

Introduction: Outcomes of rectal cancer treatment depend on preoperative staging and the effectiveness of treatments. According to disease staging, different variants of combined therapy (surgery, chemo- and radiotherapy) are used. Available parameters such as overall survival rates and diseasefree survival rates as well as the presence of recurrence are inaccurate and should be jointly considered.

Material and methods: Data from 138 patients with rectal cancer (I-III WHO), who were radically operated on in the period 2001-2004 in Bydgoszcz Oncology Centre were analysed. Among this group 84 patients were radically operated on one week after preoperative radiotherapy $5 \times 5$ Gy (sRT). We established a new parameter, the overall treatment outcome (OTO), based on the finding that there was no recurrence (local recurrence, distant metastases) of the disease within 5 years, which is generally considered a good result for the treatment of rectal cancer.

Results: Among all patients $(n=138)$ and patients following sRT $(n=84)$ $7.4 \%$...5.9\% local recurrence and $24 \%$...29\% distant metastases were observed in 5-year follow-up. Recurrence was found in $30 \%$ and $31 \%$ of patients, respectively. Analysis of results on the basis of the OTO parameter demonstrated that among all groups of patients a worse treatment outcome is related to the number of lymph nodes involved, pN, pT, cancer stage (WHO) and to $\mathrm{pN}$ and patient age in the SRT group $(p<0.005)$.

Conclusions: In using a combined therapy, it is possible to optimise rectal cancer treatment outcomes. The OTO parameter is a useful tool for defining these results of cancer combination treatment.

Key words: rectal cancer, treatment outcomes, combined therapy.

\author{
Corresponding author: \\ Michal Jankowski MD, PhD \\ Department of Surgical \\ Oncology \\ Oncology Center - \\ Prof. Franciszek Lukaszczyk \\ Memorial Hospital \\ 8 Gminna St \\ 86-005 Trzciniec, Poland \\ E-mail: \\ michaljankowski@post.pl
}




\section{Introduction}

Rectal cancer has one of the highest dynamic rates of increase of malignant neoplasm incidence. Although in the last 30 years there has been an improvement in 5 -year survival rates by around $30 \%$, still around $40 \%$ of patients do not survive this period of time [1-3]. Patient prognosis deteriorates with cancer staging. Relative 5-year survival in patients with locoregional disease (circa $37 \%$ of patients) and dissemination (c. $20 \%$ ) amounts to c. $70 \%$ and $12 \%$ [1-5], respectively. Effective rectal cancer treatment is a combination of treatments and based on the use of radiotherapy, chemotherapy and state-of-the-art surgical techniques.

The assessment and comparison of treatment results is a basic problem which all researchers face in attempting to define the patients' chances of survival. Available parameters such as overall survival (OS) and disease-free survival (DFS), as well as the presence of recurrence, are inaccurate and should be jointly considered. This is a problem specifically affecting cancer patients as the severity and number of complications in cancer treatment can significantly influence the treatment outcome. In cancer patients, the most desirable treatment outcome is long-term DFS. In this paper we present a new parameter, with the help of which we analysed the results of radical rectal cancer treatment.

\section{Material and methods}

\section{The study group}

Data from 138 patients with rectal cancer (WHO classification: TNM stage I-III) were used; these patients underwent radical surgical procedures at Bydgoszcz Oncology Centre between 2001 and 2004. Seven individual surgeons were involved and preparations were evaluated by five individual pathologists. All patients underwent

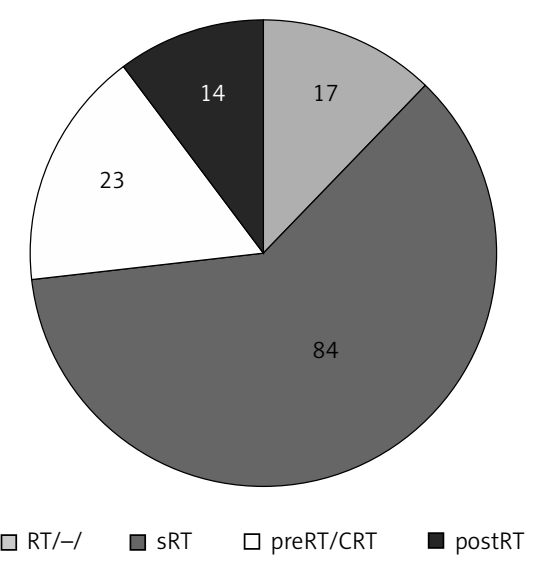

Figure 1. Radiotherapy performed in the study group $(n=138)$ surgery using the total mesorectal excision (TME) technique. In the majority of cases, radiotherapy was also performed (Figure 1).

In this group, 84 patients underwent a short course of $5 \times 5$ Gy preoperative radiotherapy (sRT). This type of radiotherapy was used in cases with resectable tumours identified in preoperative examinations. All patients received outpatient follow-up examinations at Bydgoszcz Oncology Centre. Patients' follow-ups lasted at least 5 years; patient profiles are presented in Table I.

\section{Overall survival and disease-free survival}

Overall survival and DFS rates were determined for all patients. At 60 months following surgery, $64 \%$ and $65 \%$ of patients respectively were subject to follow-up monitoring (Table II).

\section{Overall treatment outcome}

No disease recurrence within 5 years is generally considered a successful result in the treatment of colorectal cancer. Patient outcomes can therefore be assessed depending on the presence or absence of symptoms measured on a dichotomous scale (0 - parameter has not occurred, 1 - parameter has occurred):

- recurrence (0 - no, 1 - yes),

- the presence of metachronous metastases $(0-$ no, 1 - yes),

- OS less than 5 years ( 0 - no, 1 - yes),

- DFS less than 5 years ( 0 - no, 1 - yes).

Optimum patient outcome would be the nonoccurrence of the aforementioned symptoms (all values are zero), whereas the worst patient outcome would be the occurrence of all of the above symptoms (value $=4$ ). In order to assess each patient's treatment effectiveness, a standard mathematical formula can be devised:

$$
O W L=\frac{\sum_{i=1}^{4} O c_{i}}{4}
$$

where $O C_{i}$ is a dichotomous assessment of an individual's symptoms occurrence. On the basis of the above formula, a new parameter was established: overall treatment outcomes (OTO) lower case can now be measured in values such as 0 , $0.25,0.5,0.75$, and 1 . A good outcome therefore (OTO) is 0 , with values ranging from 0.25 to 1.0 considered as bad results. Based on data assessed in our study, relevant values for OTO were ascribed to all patients.

In analysing patient groups and assessing the usefulness of OTO, the following statistical methods were applied:

- Kaplan-Meier survival curves, 
Table I. Patient data $(n=138)$ including patients who underwent short course $5 \times 5$ Gy preoperative radiotherapy $(n=84)$

\begin{tabular}{|c|c|c|}
\hline Variables & All patient $(n=138)$ & $\begin{array}{l}\text { Patients who underwent short } \\
\text { course } 5 \times 5 \text { Gy preoperative } \\
\text { radiotherapy }(n=84)\end{array}$ \\
\hline \multicolumn{3}{|l|}{ Gender, $n(\%)$ : } \\
\hline Female & $64(46)$ & $36(43)$ \\
\hline Male & $74(54)$ & $48(57)$ \\
\hline Age at surgery [years], median (range) & $62.35(35-86)$ & $63.1(35-86)$ \\
\hline \multicolumn{3}{|l|}{ Place of residence, $n(\%):$} \\
\hline Rural & $46(33)$ & $30(36)$ \\
\hline Urban & $92(67)$ & $54(64)$ \\
\hline Total hospital stay [days], median (range) & $16.8(4-56)$ & $17.1(9-56)$ \\
\hline Post-operative hospital stay [days], median (range) & $12.5(5-55)$ & $13.5(6-55)$ \\
\hline \multicolumn{3}{|l|}{ Type of surgical procedure, $n(\%)$ : } \\
\hline$A R$ & $72(52)$ & $34(40)$ \\
\hline APR & $62(45)$ & $46(55)$ \\
\hline $\mathrm{HR}$ & $4(3)$ & $4(5)$ \\
\hline \multicolumn{3}{|l|}{ Operation time [min], median (range): } \\
\hline$A R$ & $150(90-295)$ & $150(90-295)$ \\
\hline APR & $195(115-250)$ & $190(115-250)$ \\
\hline $\mathrm{HR}$ & $240(125-480)$ & $240(125-480)$ \\
\hline In total & $170(90-480)$ & $175(100-480)$ \\
\hline \multicolumn{3}{|c|}{ Location of the tumour, relative to the peritoneal pouch, $n(\%)$ : } \\
\hline Above & $37(27)$ & $19(23)$ \\
\hline Below & $80(58)$ & $52(62)$ \\
\hline Not stated & $21(15)$ & $13(15)$ \\
\hline Distance from the pectinate line $[\mathrm{cm}]$, median (range) & $6.4(1-15)$ & $5.7(1-15)$ \\
\hline Number of lymph nodes found, median (range) & $11.1(1-29)$ & $11.3(2-29)$ \\
\hline \multicolumn{3}{|l|}{ Cancer stages (pTNM 2000), $n$ (\%): } \\
\hline I & $36(26)$ & $19(22)$ \\
\hline ॥ & $29(21)$ & $18(22)$ \\
\hline III & $73(53)$ & $47(56)$ \\
\hline Perioperative complications (30 days), $n$ (\%) & $38(27)$ & $21(25)$ \\
\hline Re-operation, $n$ (\%) & $11(8)$ & $7(8.3)$ \\
\hline Anastomotic dehiscence requiring re-operation, $n(\%)$ & $4(5.5)$ & $2(5.8)$ \\
\hline Post-operative chemotherapy, $n(\%)$ & $62(45)$ & $49(58)$ \\
\hline Perioperative deaths -30 days, $n(\%)$ & $2(1.4)$ & $1(1.2)$ \\
\hline
\end{tabular}

$A R$ - anterior resection, $A P R$ - abdominoperineal resection, $H R$ - Hartmann resection. 
Table II. Disease recurrence and overall survival (OS) rates after 5 years

\begin{tabular}{|lcc|}
\hline Parameter & $\begin{array}{c}\text { All patient } \\
(n=138)\end{array}$ & $\begin{array}{c}\text { Patients who underwent short course 5 } \times 5 \text { Gy } \\
\text { preoperative radiotherapy }(n=84)\end{array}$ \\
\hline Local recurrence (LR) & $13(9.4 \%)$ & $5(5.9 \%)$ \\
\hline Distant metastases (DM) & $35(25 \%)$ & $25(29 \%)$ \\
\hline Neoplastic process recurrence (LR, LR + DM, DM) & $42(30 \%)$ & $26(31 \%)$ \\
\hline Follow-up monitoring after 5 years (OS) & $88(64 \%)$ & $55(65 \%)$ \\
\hline
\end{tabular}

Table III. Patient outcomes by radiotherapy type

\begin{tabular}{|c|c|c|c|}
\hline Outcomes & $N$ & $\begin{array}{l}\text { Local recurrence, } \\
\qquad n(\%)\end{array}$ & $\begin{array}{c}\text { Distant metastases, } \\
n(\%)\end{array}$ \\
\hline \multicolumn{4}{|l|}{ Preoperative radiotherapy: } \\
\hline Short course 5 × 5 Gy (sRT) & 84 & $5(5.9)$ & $24(29)$ \\
\hline $\begin{array}{l}\text { Long-term radiotherapy or radiochemotherapy } \\
\text { (pre-RT/CRT) }\end{array}$ & 23 & $3(13)$ & $3(13)$ \\
\hline Postoperative radiotherapy (post-RT) & 14 & 0 & $2(14)$ \\
\hline Without radiotherapy & 17 & $5(29)$ & $3(18)$ \\
\hline In total & 138 & $13(9.4)$ & $35(25)$ \\
\hline
\end{tabular}

- parametric test for two fractions,

- Snedecor F-test,

- Z-test,

- parametric tests: Student's t-test, Cochran-Cox test,

- $\chi^{2}$ non-parametric test of independence, $\chi^{2}$ test with Yates correction (Fisher's exact test),

- non-parametric Shapiro-Wilk test, Mann-Whitney test.

The significance level in analyses was 0.05 (a statistically significant difference was $p<0.05-$ $\mathrm{ss}$, in cases where $p>0.005-\mathrm{ns}$ (not significant)).

\section{Results}

Among patients who underwent radical rectal cancer resection between 2001 and 2004, local recurrence (LR) and distant metastases (DM) were diagnosed in $9.4 \%$ and $25 \%$ of patients, respectively. Local recurrence less frequently affected patients treated with SRT (5.9\%). Other groups included too few patients and those who were not subjected to analysis.

The highest rate of LR was in patients who were not treated with radiotherapy. This group was very heterogeneous, and combined therapy was not used for a number of reasons such as prior pelvic irradiation, comorbidities, and lack of patient written consent, amongst others.

All patient groups in which DM was diagnosed showed variation in the rate of occurrence. In the two largest groups of patients (all patients: $n=138$; sRT group: $n=84$ ), the percentage incidence of DM occurrence was similar (Table III).
In all groups including patients subject to sRT, the survival probability estimates using the Kaplan-Meier method were similar (Figure $2 \mathrm{~A}, \mathrm{~B}$ ).

Analysis of results on the basis of the OTO parameter demonstrated that in all patients a worse treatment outcome was related to the presence and number of metastatically affected lymph nodes in histopathological preparation ( $\mathrm{N}$ parameter) together with the depth of invasion of the primary tumour beyond the rectum wall (T parameter) (Table IV).

Among SRT patients, the absence and lower number of metastatically affected lymph nodes ( $N$ parameter) was statistically significant for a good outcome (OTO $=0$ ), similarly with a younger patient age at the time of surgery.

\section{Discussion}

The results of cancer treatment are traditionally measured in relation to OS rates and DFS rates within 5 years. The greatest impact on the successful treatment of patients with malignant neoplasms is the avoidance of cancer recurrence in the form of LR and DM.

It should be noted that OS rates, especially in the elderly, are affected by comorbidities, complications following treatment and general health.

Due to the specific nature of the OTO parameter its assessment is based on four elements, i.e., local recurrence, distant metastases, 5-year DFS and OS.

\section{Treatment results}

An LR following surgical treatment for rectal cancer significantly worsens the patient's prog- 
A

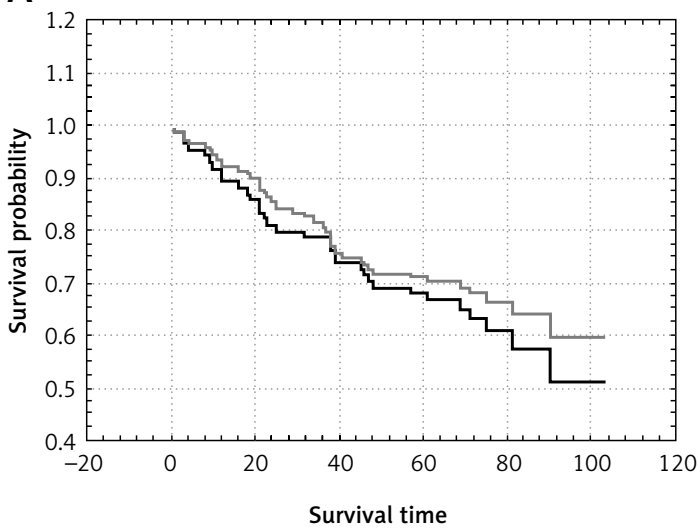

B

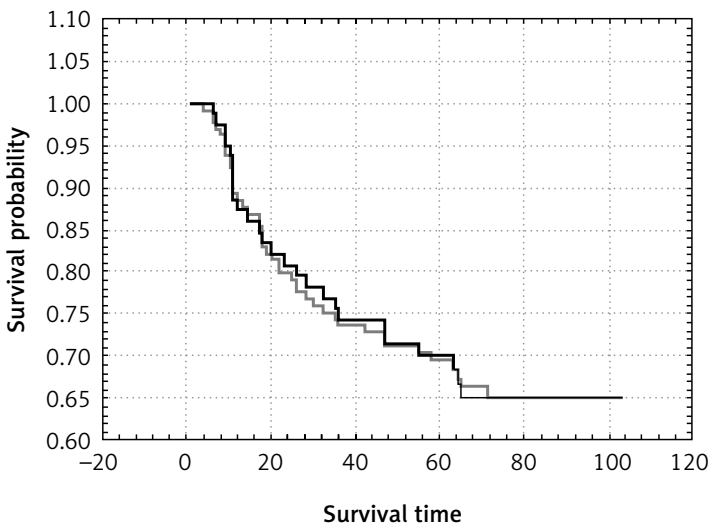

Figure 2. Survival probability estimates according to the Kaplan-Meier method: all patients $(n=138$, black line), patients following SRT ( $n=84$, grey line). A - overall survival rate (OS), B - disease free survival rate (DFS)

nosis [6]. The number of recurrences following resection of colorectal cancer may vary from 3.7\% to $50 \%[7,8]$, and their treatment is frequently ineffective $[4,9]$. A reduction in the $L R$ rate may be achieved by using a relevant technique of resection of the rectum and pre- or postoperative radiotherapy $[10,11]$.

Application of appropriate surgical techniques is conditional upon factors such as preserving the radial margin, and resection by TME [12-14].

In the Swedish Rectal Cancer Trial study, owing to the use of pre-sRT, a lower rate of LR (11\%) was observed in comparison to patients who solely underwent surgery $(27 \%)[15,16]$. It should be noted, however, that surgical procedures in this study were not standardised, and not all patients underwent TME.

In the Dutch Colorectal Study Group, TME was performed on 1,805 patients with resectable rectal cancer. In patients subject to SRT, $2.4 \%$ LR was observed, compared to $8.2 \%$ among patients who were subject to non-combination treatment [17].

In our study, LR were found in 13 patients (9.4\%). Among patients who were subject to sRT, LR were observed in 5 patients $(5.9 \%)$, whereas in the group treated with pre RT/CRT, LR was diagnosed in 3 patients (13\%), and these rates are similar to the results reported earlier $[18,19]$.

\section{Treatment results - distant metastases}

The emergence of DM is the major adverse prognostic factor in patients with malignancies. The development of DM following radical treatment of rectal cancer is observed in 30-60\% of patients, with the most common locations being the liver and lungs [20]. The OS rate of these patients is much lower and radical treatment options are limited.

During clinical observations, the prognostic significance of multiple factors in the development of DM in patients following radical resection of rectal cancer was confirmed, especially in the primary cancer stage [21], but studies are still ongoing [22, 23]. Moreover, the presence of a local recurrence affects the incidence rate of DM [24]. The role played by lymph node condition and the size of the radial margin was also observed [25].

However, large meta-analyses failed to confirm a reduction in the incidence of DM when subjected to radiotherapy [18].

In our study group 35 (25\%) patients under observation developed DM, of whom 26 (80\%) subsequently died. Among patients who underwent SRT the DM rates were very similar, i.e., $29 \%$ and $76 \%$, respectively. These statistics are similar to those reported elsewhere in the literature $[2,3,5]$.

\section{Overall survival}

Recurrence is the major factor affecting longterm survival of patients following the radical treatment of malignant neoplasms. Other factors, discussed in this paper, are also crucial; these are comorbidities, complications during treatment, or the patient's age. Owing to state-of-the-art techniques such as TME, radiotherapy and perioperative care improvement, the rate of 5-year survival for patients with rectal cancer has increased in the last 20 years, from $48 \%$ [15] to over $60 \%$ [26].

The impact of radiation therapy on survival extension has not been adequately assessed. Previously published results indicate survival extension $[15,18]$, but also conversely the absence of this correlation $[27,28]$.

In recent years research studies have been published which demonstrate the improvement in survival rates of patients treated for rectal cancer, which indirectly demonstrates the increasing effectiveness of combined treatment [29-31].

In our study, $64 \%$ of patients survived 5 years (OS), with the rate for patient who underwent 
Michal Jankowski, Dariusz Bała, Manuela Las-Jankowska, Wojciech Maria Wysocki, Tomasz Nowikiewicz, Wojciech Zegarski

Table IV. The impact of selected factors on the overall treatment outcome (OTO)

\begin{tabular}{|c|c|c|c|c|c|c|}
\hline \multirow[t]{2}{*}{ Parameter } & \multicolumn{3}{|c|}{$\begin{array}{l}\text { All patient } \\
(n=138)\end{array}$} & \multicolumn{3}{|c|}{$\begin{array}{l}\text { Patients who underwent short course } \\
5 \times 5 \text { Gy preoperative radiotherapy } \\
\qquad(n=84)\end{array}$} \\
\hline & ОТО = 0 & ОТО > 0 & $P$-value & OTO = 0 & ОТО > 0 & $P$-value \\
\hline Age at surgery [years], median (SD) & $60.3(11.4)$ & $63.4(13)$ & 0.14 & $60.9(9.7)$ & $65.6(9.5)$ & $<0.03$ \\
\hline \multicolumn{7}{|l|}{ Gender, $n(\%)$ : } \\
\hline Both & & & 0.15 & & & 0.89 \\
\hline Female & $31(40.8)$ & $33(59.2)$ & & $19(54.8)$ & $17(47.2)$ & \\
\hline Male & $45(60.8)$ & $29(39.2)$ & & $26(52.8)$ & $22(45.8)$ & \\
\hline $\begin{array}{l}\text { Distance from the pectinate line }[\mathrm{cm}] \\
\text { median }(\mathrm{SD})\end{array}$ & $6.81(4.25)$ & $5.87(4.12)$ & 0.19 & $6.16(4.2)$ & $5.23(3.73)$ & 0.23 \\
\hline \multicolumn{7}{|c|}{ Location relative to the peritoneal pouch, $n(\%)$ : } \\
\hline Total & & & 0.39 & & & 0.86 \\
\hline Below & $43(53.7)$ & $37(46.3)$ & & $29(55.8)$ & $23(44.2)$ & \\
\hline Above & $23(62.2)$ & $14(37.8)$ & & $11(57.9)$ & $8(42.1)$ & \\
\hline \multicolumn{7}{|l|}{ Type of surgical procedure, $n(\%)$ : } \\
\hline Total & & & 0.37 & & & 0.22 \\
\hline AR & $42(58.3)$ & $32(41.7)$ & & $22(47.8)$ & $24(52.2)$ & \\
\hline APR & $30(51.6)$ & $30(48.4)$ & & $21(61.8)$ & $13(38.2)$ & \\
\hline \multicolumn{7}{|c|}{ Perioperative complications (30 days), $n$ (\%): } \\
\hline Total & & & 0.61 & & & 0.37 \\
\hline Yes & $15(60)$ & $10(40)$ & & $10(45.4)$ & $12(54.6)$ & \\
\hline No & $61(54)$ & $52(46)$ & & $35(56.4)$ & $27(43.6)$ & \\
\hline \multicolumn{7}{|l|}{ Re-operation, $n$ (\%): } \\
\hline Total & & & 0.94 & & & 0.84 \\
\hline Yes & $6(54.5)$ & $5(45.5)$ & & $4(57.1)$ & $3(42.9)$ & \\
\hline No & $70(55.1)$ & $57(44.9)$ & & $41(53.2)$ & $36(46.7)$ & \\
\hline \multicolumn{7}{|c|}{$\mathrm{N}$ parameter according to pTNM classification, $n(\%)$ : } \\
\hline Total & & & 0.006 & & & $<0.04$ \\
\hline No & $42(64.6)$ & $23(35.4)$ & & $25(67.6)$ & $12(32.4)$ & \\
\hline N1 & $22(50)$ & $22(50)$ & & $13(50)$ & $13(50)$ & \\
\hline N2 & $12(41.4)$ & $17(58.6)$ & & $7(33.3)$ & $14(66.7)$ & \\
\hline $\mathrm{N} 1 / \mathrm{N} 2$ & & & & & & 0.022 \\
\hline No/N2 & & & 0.035 & & & 0.01 \\
\hline \multicolumn{7}{|c|}{ T parameter according to pTNM classification, $n(\%)$ : } \\
\hline $\mathrm{T} 3 / \mathrm{T} 1-2$ & & & 0.0701 & & & 0.44 \\
\hline $\mathrm{T} 3-4 / \mathrm{T} 1-2$ & & & 0.0304 & & & 0.4 \\
\hline $\mathrm{T} 1$ & $3(75)$ & $1(25)$ & & 2 (100) & 0 & \\
\hline $\mathrm{T} 2$ & $37(63.8)$ & $21(36.2)$ & & $19(57.6)$ & $14(42.4)$ & \\
\hline T3 & $30(48.4)$ & $32(51.6)$ & & $21(51.2)$ & $20(48.8)$ & \\
\hline $\mathrm{T} 4$ & $3(30)$ & $7(70)$ & & $2(28.6)$ & $5(71.4)$ & \\
\hline
\end{tabular}


Table IV. Cont.

\begin{tabular}{|c|c|c|c|c|c|c|}
\hline \multirow[t]{2}{*}{ Parameter } & \multicolumn{3}{|c|}{$\begin{array}{l}\text { All patient } \\
(n=138)\end{array}$} & \multicolumn{3}{|c|}{$\begin{array}{l}\text { Patients who underwent short course } \\
5 \times 5 \text { Gy preoperative radiotherapy } \\
\qquad(n=84)\end{array}$} \\
\hline & ОТО = 0 & OTO $>0$ & $P$-value & ОТО = 0 & Ото > 0 & $P$-value \\
\hline \multicolumn{7}{|l|}{ Cancer stage, $n(\%)$ : } \\
\hline$|/| I I \mid$ & & & 0.045 & & & 0.053 \\
\hline 1 & $24(66.7)$ & $12(33.3)$ & & $13(68.4)$ & $6(31.6)$ & 0.07 \\
\hline II & $18(62.1)$ & $11(37.9)$ & & $12(66.7)$ & $6(33.3)$ & \\
\hline III & $34(46.6)$ & $39(53.4)$ & & $20(42.6)$ & $27(57.4)$ & \\
\hline $\begin{array}{l}\text { Number of lymph nodes found, } \\
\text { median (SD) }\end{array}$ & $109(7.27)$ & $11.1(6.35)$ & 0.87 & $45(10.29)$ & $39(12.64)$ & 0.11 \\
\hline Number of lymph nodes involved & $1.7(2.57)$ & $34(4.83)$ & 0.009 & $45(1.6)$ & $39(4.59)$ & $<0.0001$ \\
\hline
\end{tabular}

SRT being $65 \%$. These results are similar to those found elsewhere in the literature [32-34].

\section{Disease-free survival}

The use of radiotherapy in rectal cancer treatment reduces the risk of LR improving patients' chance for longer DFS. In the Colorectal Cancer Collaborative Group's meta-analysis, neoadjuvant radiotherapy combined with surgical procedures, when compared to a surgical procedure alone, confirmed its importance in extending cause-specific survival (CSS) [27]. Cammà's meta-analysis yielded similar results [18].

When comparing preoperative and postoperative radiotherapy, it appears that a slightly higher rate of DFS can be achieved in cases of neoadjuvant treatment [19].

In our study, we found a $57 \%$ rate for 5-year DFS. In stages I, II, and III (WHO classification), the DFS rates were $70 \%, 62 \%$ and $49 \%$, respectively. Among patients in stages I, II and III, who underwent preoperative radiotherapy, a rate of $57 \%$ for 5 -year DFS was reported with rates of $74 \%, 67 \%$ and $47 \%$, respectively; these results were slightly better than rates in the study group overall.

\section{Age}

The influence of age in patients with rectal cancer during treatment is quite frequently discussed in the literature. The risk of developing this cancer increases with age [1], and with the population's rising median age, the occurrence increases accordingly.

Many researchers believe that developing rectal cancer over 80 years of age does not diminish the chances of curing the disease following radical surgery. The overall perioperative mortality rate and 5 -year OS rate are lower than in younger patients $[35,36]$.
Similarly, cancer in patients over 65 years of age does not markedly change the short-term disease prognosis, although in this age group 5-year OS and 5-year DFS rates are lower [37, 38].

In our study, younger age was conducive to a good OTO in patients subject to SRT.

\section{Metastases to lymph nodes}

Metastases to lymph nodes are widely considered to be a poor prognostic factor in malignant neoplasms.

The presence of metastatically affected lymph nodes is the basis for the differentiation of cancer stages classified as N0 - N1 - N2, depending on the number of lymph nodes involved [39]. According to the WHO classification of colorectal cancer, patients with metastases in regional lymph nodes are classified as having stage III cancer. It is considered that rectal cancer has a greater ability to form metastases in regional lymph nodes than colon cancer [40].

Tang et al. reported 538 cases of patients with stage III rectal cancer who underwent surgery between 1980 and 1989 . The relative 5 -year and 10 -year survival rates were $52 \%$ and $42 \%$, respectively. They compared the number of metastatically affected lymph nodes and thus determined a statistically significant correlation with relative survival rates [41].

Suzuki et al. reported 118 cases of patients with stage III colon cancer. When relating 5-year survival rates to the number of metastatically affected lymph nodes they considered it to be an independent prognostic factor [42].

Our analysis of patients' data showed a statistically significant correlation between the presence and number of metastases relative to regional lymph nodes and treatment outcomes (OTO). This correlation occurred both in the overall group of patients $(n=138)$ and patients undergoing $5 \times 5$ Gy preoperative radiotherapy $(n=84)$. 


\section{Local staging}

Local staging ( $\mathrm{T}$ parameter in WHO classifications) is a recognised prognostic factor, even though its significance is less than that of the presence of metastases in regional lymph nodes $(N)$.

Yalman et al. analysed long-term treatment results in 290 patients with rectal cancer between 1990 and 2005, who underwent postoperative radiotherapy (50.4 Gy). The factors which most significantly influenced OS and DFS were the number of affected lymph nodes $(\mathrm{pN})$ and the depth of invasion of the primary tumour (pT) [43].

In our study group $(n=138)$, local stage $(T)$ was an important factor affecting the OTO parameter. This impact had not been observed in the subgroup of patients following SRT, which may indirectly suggest the importance of this component in the combined treatment.

In conclusion, our analysis of treatment results using the ОTO parameter was consistent with those described in the literature [44]. There were statistical correlations with respect to factors such as age, the presence and number of lymph nodes involved, or local staging, and their impact on OTO.

We believe that the OTO parameter is a useful tool for assessing the effectiveness of cancer combined therapy.

Although patient groups cannot be directly compared, attention should be paid to differences manifest in the analysis of OTO. In the group of patients who underwent SRT, an individual's greater age was an unfavourable factor which may indicate a lower tolerance for this kind of treatment as well as increasing the incidence of death from causes other than cancer [26].

In the group of patients who underwent radiotherapy, local stage ( $T$ parameter according to TNM) and the number of lymph nodes involved had a smaller, statistically insignificant impact on the OTO; this implicitly proves the local effectiveness of this form of treatment.

The introduction of this new ОТО parameter allows fast analysis and comparison of treatment results. This approach may prove essential both in searching for prognostic factors and in finding homogeneous groups with similar prognoses, with an overall aim of defining predictive factors.

\section{Conflict of interest}

The authors declare no conflict of interest.

\section{References}

1. U.S. National Cancer Institute Surveillance, Epidemiology and End Results (SEER) Program. U. S. National Cancer Institute. Available at: http://www.seer.cancer. gov/ [Accessed: 14.08.2017].

2. Iversen LH, Green A, Ingeholm P, Østerlind K, Gögenur I. Improved survival of colorectal cancer in Denmark during 2001-2012 - the efforts of several national initiatives. Acta Oncol 2016; 9: 1-14.

3. Elferink MA, Krijnen P, Routers MW, et al. Variation in treatment and outcome of patients with rectal cancer by region, hospital type and volume in the Netherlands. Eur J Surg Oncol 2010; 36 (Suppl): S74-82.

4. Morris EJ, Sandin F, Lambert PC, et al. A population-based comparison of the survival of patients with colorectal cancer in England, Norway and Sweden between 1996 and 2004. Gut 2011; 60: 1087-93.

5. Tiefenthal M, Nilsson PJ, Johansson R, Glimelius B, Påhlman $L$. The effects of short-course preoperative irradiation on local recurrence rate and survival in rectal cancer: a population-based nationwide study. Dis Colon Rectum 2011; 54: 672-80.

6. Pollett WG, Nicholls RI. The relationship between the extent of distal clearance and survival and local recurrence rates after curative anterior resection for carcinoma of the rectum. Ann Surg 1983; 198: 159-63.

7. Eu KW, Seow-Choen F, Ho JM, Ho YH, Leong PK. Local recurrence following rectal resection for cancer. J R Coll Surg Edinb 1998; 43: 393-6.

8. Killingback M, Barron P, Dent OF. Local recurrence after curative resection of cancer of the rectum without total mesorectal excision. Dis Colon Rectum 2001; 44: 473-83.

9. Cohen AM, Minsky BD. Aggressive surgical management of locally advanced primary and recurrent rectal cancer. Dis Colon Rectum 1990; 33: 432-8.

10. Inoue $Y$, Kusunoki M. Resection of rectal cancer: a historical review. Surg Today 2010; 40: 501-6.

11. Rutkowski A, Nowacki MP, Chwalinski M, et al. Acceptance of a 5-mm distal bowel resection margin for rectal cancer: is it safe? Colorectal Dis 2012; 14: 71-8.

12. Heald RJ, Ryall RDH. Recurrence and survival after total mesorectal excision for rectal cancer. Lancet 1986; 1 : 1479-82.

13. Heald RJ, Karanjia ND. Results of radical surgery for rectal cancer. World J Surg 1992; 16: 848-57.

14. Bębenek M, Tupikowski W, Cisarż K, et al. Preoperative treatment does not improve the therapeutic results of abdominosacral amputation of the rectum. World J Surg 2012; 36: 1686-92.

15. Swedish Rectal Cancer Trial, Cedermark B, Dahlberg M, Glimelius B, Påhlman L, Rutqvist LE, Wilking N. Improved survival with preoperative radiotherapy in resectable rectal cancer. N Engl J Med 1997; 336: 980-7.

16. Initial report from a Swedish multicentre study examining the role of preoperative irradiation in the treatment of patients with resectable rectal carcinoma. Swedish Rectal Cancer Trial. Br J Surg 1993; 80: 1333-6.

17. Kapiteijn E, Marijnen CA, Nagtegaal ID, et al.; Dutch Colorectal Cancer Group. Preoperative radiotherapy combined with total mesorectal excision for resectable rectal cancer. N Engl J Med 2001; 345: 638-46.

18. Cammà C, Giunta M, Fiorica F, Pagliaro L, Craxì A, Cottone $M$. Preoperative radiotherapy for resectable rectal cancer: a meta-analysis. JAMA 2000; 284: 1008-15.

19. Sebag-Montefiore D, Stephens JR, Steele R, et al. Preoperative radiotherapy versus selective postoperative chemoradiotherapy in patients with rectal cancer (MRC CR07 and NCIC-CTG C016): a multicentre, randomised trial. Lancet 2009; 373: 811-20.

20. Van Cutsem E, Nordlinger B, Adam R, et al. Towards a pan-European consensus on the treatment of patients with colorectal liver metastases. Eur J Cancer 2006; 42: 2212-21. 
21. Zhang K, Chen Y, Huang X, et al. Expression and clinical significance of cytochrome $c$ oxidase subunit IV in colorectal cancer patients. Arch Med Sci 2016; 12: 68-77.

22. Bobowicz M, Skrzypski M, Czapiewski P, et al. Prognostic value of 5-microRNA based signature in T2-T3NO colon cancer. Clin Exp Metastasis 2016; 33: 765-77.

23. Köckerling F, Reymond MA, Altendorf-Hofmann A, Dworak $\mathrm{O}$, Hohenberger W. Influence of surgery on metachronous distant metastases and survival in rectal cancer. J Clin Oncol 1998; 16: 324-9.

24. van den Brink M, Stiggelbout AM, van den Hout WB, et al. Clinical nature and prognosis of locally recurrent rectal cancer after total mesorectal excision with or without preoperative radiotherapy. J Clin Oncol 2004; 22: 3958-64.

25. Eriksen MT, Wibe A, Haffner J, Wiig JN; Norwegian Rectal Cancer Group. Prognostic groups in 1,676 patients with T3 rectal cancer treated without preoperative radiotherapy. Dis Colon Rectum 2007; 50: 156-67.

26. Peeters KC, Marijnen CAM, Nagtegaal ID, et al. The TME Trial after a median follow-up of 6 years: increased local control but no survival benefit in irradiated patients with resectable rectal carcinoma. Ann Surg 2007; 246: 693-701.

27. Colorectal Cancer Collaborative Group. Adjuvant radiotherapy for rectal cancer: a systematic overview of 8507 patients from 22 randomised trials. Lancet 2001; 358. 1291-304.

28. van Gijn W, Marijnen CA, Nagtegaal ID, et al.; Dutch Colorectal Cancer Group. Preoperative radiotherapy combined with total mesorectal excision for resectable rectal cancer: 12-year follow-up of the multicentre, randomised controlled TME trial. Lancet Oncol 2011; 12: 575-82.

29. den Dulk M, Krijnen P, Marijnen CA, et al. Improved overall survival for patients with rectal cancer since 1990 the effects of TME surgery and pre-operative radiotherapy. Eur J Cancer 2008; 44: 1710-6.

30. Nedrebø BS, Søreide K, Eriksen MT, et al. Survival effect of implementing national treatment strategies for curatively resected colonic and rectal cancer on behalf of the Norwegian Colorectal Cancer Registry. Br J Surg 2011; 98: 716-23.

31. Tjandra JJ, Chan MK. Follow-up after curative resection of colorectal cancer: a meta-analysis. Dis Colon Rectum 2007; 50: 1783-99.

32. Bujko K, Nowacki MP, Nasierowska-Guttmejer A, Michalski $W$, Bebenek $M$, Kryj $M$. Long-term results of a randomized trial comparing preoperative short-course radiotherapy with preoperative conventionally fractionated chemoradiation for rectal cancer. Br J Surg 2006; 93: 1215-23.

33. Ngan S, Fisher R, Goldstein D, et al. A randomized trial comparing local recurrence (LR) rates between shortcourse (SC) and long-course (LC) preoperative radiotherapy (RT) for clinical T3 rectal cancer: an intergroup trial (TROG, AGITG, CSSANZ, RACS). J Clin Oncol 2010; 28 (Suppl): 3509.

34. Çetin DA, Yildirim M, Yakan S, Çiyiltepe H, Aydoğan S. Effects of prognostic factors on overall and disease-free survival in patients with stage I-III colorectal cancer. Arch Med Sci Civil Dis 2016; 1: 131-8.

35. Barrier A, Ferro L, Houry S, Lacaine F, Huguier M. Rectal cancer surgery in patients more than 80 years of age. Am J Surg 2003; 185: 54-7.

36. Ferenschild FT, Dawson I, de Wilt JH, de Graaf EJ, Groenendijk RP, Tetteroo GW. Total mesorectal excision for rectal cancer in an unselected population: quality assessment in a low volume center. Int J Colorectal Dis 2009; 24: 923-9.
37. Bufalari A, Giustozzi G, Burattini MF, et al. Rectal cancer surgery in the elderly: a multivariate analysis of outcome risk factors. J Surg Oncol 2006; 93: 173-80.

38. Kerr J, Engel J, Eckel R, Hölzel D. Survival for rectal cancer patients and international comparisons. Ann Oncol 2005; 16: 664-72.

39. Sobin LH, Gospodarowicz MK, Wittekind C. TNM Classification of Malignant Tumours. $7^{\text {th }}$ ed. Wiley-Blackwell; 2009.

40. Wang H, Wei XZ, Fu CG, Zhao RH, Cao FA. Patterns of lymph node metastasis are different in colon and rectal carcinomas. World J Gastroenterol 2010; 16: 5375-9.

41. Tang R, Wang JY, Chen JS, et al. Survival impact of lymph node metastasis in TNM stage III carcinoma of the colon and rectum. J Am Coll Surg 1995; 180: 705-12.

42. Suzuki O, Sekishita Y, Shiono T, Ono K, Fujimori M, Kondo $S$. Number of lymph node metastases is better predictor of prognosis than level of lymph node metastasis in patients with node-positive colon cancer. J Am Coll Surg 2006; 202: 732-6.

43. Yalman D, Demirci S, Bolukbasi Y, Caliskan C, Ozkok S. Postoperative radiotherapy in rectal cancer: long-term results of 290 patients. Hepatogastroenterology 2010; 57: 1099-105.

44. Glynne-Jones R, Wyrwicz L, Tiret E, et al.; ESMO Guidelines Committee. Rectal cancer: ESMO Clinical Practice Guidelines for diagnosis, treatment and follow-up. Ann Oncol 2017; 28 (Suppl): 22-40. 